LAWRENCE LIVERMORE N A TIO N A L LABORATORY
DYNA3D Material Model 71 Solid Element Test Problem

E. Zywicz

January 29, 2008 
This document was prepared as an account of work sponsored by an agency of the United States government. Neither the United States government nor Lawrence Livermore National Security, LLC, nor any of their employees makes any warranty, expressed or implied, or assumes any legal liability or responsibility for the accuracy, completeness, or usefulness of any information, apparatus, product, or process disclosed, or represents that its use would not infringe privately owned rights. Reference herein to any specific commercial product, process, or service by trade name, trademark, manufacturer, or otherwise does not necessarily constitute or imply its endorsement, recommendation, or favoring by the United States government or Lawrence Livermore National Security, LLC. The views and opinions of authors expressed herein do not necessarily state or reflect those of the United States government or Lawrence Livermore National Security, LLC, and shall not be used for advertising or product endorsement purposes.

This work performed under the auspices of the U.S. Department of Energy by Lawrence Livermore National Laboratory under Contract DE-AC52-07NA27344. 


\title{
DYNA3D Material Model 71 - Solid Element Test Problem
}

\author{
Edward Zywicz \\ Methods Development Group \\ Defense Technologies Engineering Division \\ Engineering Directorate
}

January 22, 2008

\section{SUMMARY}

A general phenomenological-based elasto-plastic nonlinear isotropic strain hardening material model was implemented in DYNA3D for use in solid, beam, truss, and shell elements. The constitutive model, Model 71 , is based upon conventional $J 2$ plasticity and affords optional temperature and rate dependence (visco-plasticity). The expressions for strain hardening, temperature dependence, and rate dependence allow it to represent a wide variety of material responses. Options to capture temperature changes due to adiabatic heating and thermal straining are incorporated into the constitutive framework as well.

The verification problem developed for this constitutive model consists of four uni-axial right cylinders subject to constant true strain-rate boundary conditions. Three of the specimens have different constant strain rates imposed, while the fourth specimen is subjected to several strain rate jumps. The material parameters developed by Fehlmann (2005) for 21-6-9 Nitronic steel are utilized. As demonstrated below, the finite element (FE) simulations are in excellent agreement with the theoretical responses and indicated the model is functioning as desired. Consequently, this problem serves as both a verification problem and regression test problem for DYNA3D.

\section{CONSTITUTIVE MODEL OVERVIEW}

Material model 71 in DYNA3D (Whirley and Engelmann, 1993) is an elasto-plastic constitutive relationship with nonlinear isotropic strain hardening and optional strain rate and temperature dependence. The stress is given by

$$
\sigma=C\left(\varepsilon-\varepsilon^{p}-\varepsilon^{T}\right)
$$

where $C$ is the isotropic elastic stiffness tensor, and $\varepsilon, \varepsilon^{p}$, and $\varepsilon^{T}$ are the total strain, plastic strain, and total thermal strain tensors, respectively. The model uses standard $J 2$ assumptions for plastic flow. The plastic yield surface is given by

$$
\phi_{p}=\bar{\sigma}-\sigma_{y}\left(\bar{\varepsilon}^{p}, \dot{\bar{\varepsilon}}^{p}, T\right)
$$


where $\bar{\sigma}$ is the effective stress and $\sigma_{y}$ is the current (true) yield strength. The yield strength model, which defines the one-dimensional true stress versus true plastic strain response, has the form

$$
\sigma_{y}=\sigma_{s}\left(\bar{\varepsilon}^{p}\right) \times \sigma_{r}\left(\dot{\bar{\varepsilon}}^{p}, T\right) \times \sigma_{t}(T),
$$

where

$$
\begin{gathered}
\sigma_{s}\left(\bar{\varepsilon}^{p}\right)=s_{1}+s_{2} \bar{\varepsilon}^{p}+s_{3}\left(\bar{\varepsilon}^{p}+s_{4}\right)^{s_{5}}+s_{6} \exp \left(s_{7}\left(\bar{\varepsilon}^{p}+s_{8}\right)\right) \\
\sigma_{r}\left(\dot{\bar{\varepsilon}}^{p}, T\right)=r_{1}+\left(r_{2} \dot{\bar{\varepsilon}}^{p}+r_{3}\right)^{r_{4}}+\left(r_{5}+r_{6} T\right) \ln \left(r_{7} \dot{\bar{\varepsilon}}^{p}+r_{8}\right) \\
\sigma_{t}(T)=t_{1}+t_{2} T+t_{3} \exp \left(t_{4} / T\right)
\end{gathered}
$$

$\bar{\varepsilon}^{p}$ is the equivalent (true) plastic strain, $\dot{\bar{\varepsilon}}^{p}$ is the equivalent (true) plastic strain rate, $T$ is the current temperature, and the remaining terms are material coefficients. When the strain rate coefficients $r_{1}, r_{2}, r_{5}$, and $r_{6}$ are zero, then $\sigma_{r}\left(\dot{\bar{\varepsilon}}^{p}, T\right)=1$. Similarly, when the thermal coefficients $t_{1}, t_{2}$, and $t_{3}$ are zero, then $\sigma_{t}(T)=1$. The thermal strain is expressed in terms of the secant coefficient of thermal expansion $\bar{\alpha}$, the reference temperature $T_{\text {ref }}$ used to construct $\bar{\alpha}$, and $T$ as

$$
\varepsilon_{i j}^{T}=\bar{\alpha}(T) \times\left(T-T_{r e f}\right) \delta_{i j} .
$$

Thermal heating due to plastic work is made using an adiabatic assumption. The instantaneous temperature is given by

$$
T=T_{\text {nominal }}+\omega / \rho c_{v},
$$

where $T_{\text {nominal }}$ is the nominal temperature specified, $\rho$ is the mass density, $c_{v}$ is the specific heat, and the plastic work density is given by

$$
\omega=\int_{0}^{t} \sigma \bullet \dot{\varepsilon}^{p} d t .
$$

This multiplicative yield strength model is very general and can represent a wide variety of material behaviors since groupings may be selectively deactivated by specifying their leading coefficients as zero.

\section{TEST PROBLEM DESCRIPTION}

The specimen simulated in Zywicz (2005) to test material model 24 with hexahedral elements is employed here. It consists of a right circular cylinder 1.5 inches high and 0.5 inches in diameter, and it represents the strain gauge portion of a standard round tensile test specimen. The finite element model assumes symmetry along the specimen length and in the two in-plane directions; thus, only a 0.75 inch long, 90 degree section of the cylinder is meshed. The mesh, shown in Figure 1, contains 18 physically-stabilized 8node hexahedral elements along its length and 27 elements in its cross-section. On the planes of symmetry, displacements normal to the plane are prohibited. On the top of the cylinder, velocity boundary conditions are prescribed that generate, assuming homogeneous deformation, a constant true strain rate. (Note, these boundary conditions differ from those used by Hodge and Kay (2003).) 
LLNL-TR-400815

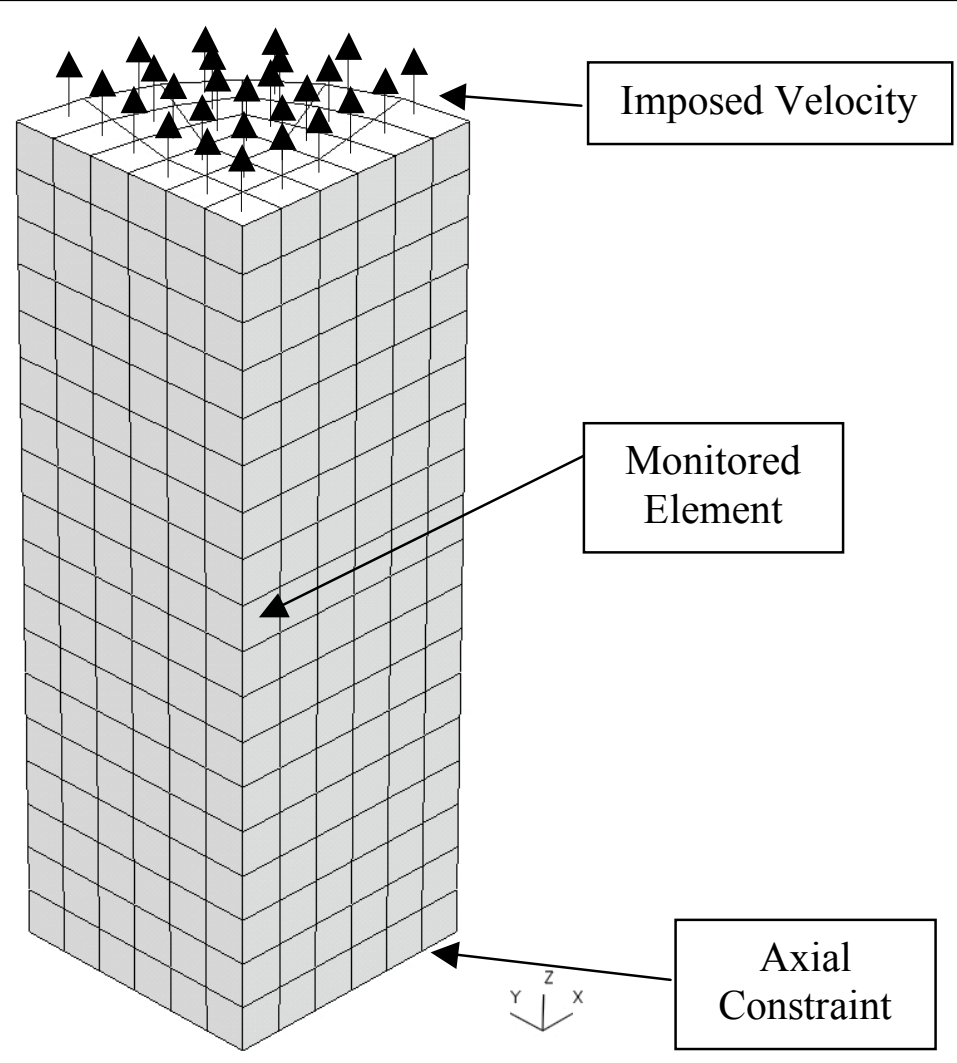

Figure 1. Test specimen mesh

The verification problem contains four separate specimens. The imposed true strain rates for the first three specimens are 100/sec, 200/sec, and 500/sec, respectively. The loading is maintained until the specimen develops a true tensile strain of 0.50 in the axial direction. Subsequently, the imposed strain rate is linearly decreased to $0.1 / \mathrm{sec}$ and held there for the remainder of the simulation. The fourth specimen is used to perform a strainrate jump test. The three previous true strain rates are imposed, in the order listed above, until each generates an additional true strain of $\sim 0.15$. The four specimens $(100 / \mathrm{sec}$, $200 / \mathrm{sec}, 500 / \mathrm{sec}$, and jump test) are oriented so that the axial direction of the specimen is parallel to the global $z, y, x$, and $z$ coordinate axes, respectively.

Using the data in Fehlmann (2005), material coefficients appropriate for 21-6-9 Nitronic steel were constructed and are listed in Table 1. In the simulations, the material is prescribed a temperature of $344 \mathrm{~K}\left(160^{\circ} \mathrm{F}\right)$. Consequently, the results from these simulations should match those reported previously when using material model 24 (Zywicz, 2005). 
Table 1. Material Model 71 Input Parameters for 21-6-9 Nitronic steel

\begin{tabular}{|c|c|c|c|}
\hline Card & Term & Variable & Value \\
\hline \multirow{3}{*}{3} & 1 & $\mathrm{E}(\mathrm{psi})$ & $28,500,000$ \\
\cline { 2 - 4 } & 2 & $\mathrm{pr}$ & 0.29 \\
\hline \multirow{4}{*}{4} & 1 & $s_{1}(\mathrm{psi})$ & 5179 \\
\cline { 2 - 4 } & 2 & $s_{2}(\mathrm{psi})$ & $2.372 \times 10^{5}$ \\
\cline { 2 - 4 } & 3 & $s_{3}(\mathrm{psi})$ & $7.710 \times 10^{4}$ \\
\cline { 2 - 4 } & 4 & $s_{4}$ & $1.000 \times 10^{-3}$ \\
\hline \multirow{3}{*}{5} & 5 & $s_{5}$ & $7.140 \times 10^{-2}$ \\
\cline { 2 - 4 } & 1 & $r_{1}$ & 1 \\
\cline { 2 - 4 } & 2 & $r_{2}(1 / \mathrm{sec})$ & $2.198 \times 10^{-4}$ \\
\hline \multirow{3}{*}{6} & 3 & $r_{4}$ & $2.198 \times 10^{-8}$ \\
\cline { 2 - 4 } & 3 & $t_{3}$ & 0.20964 \\
\hline & 4 & $t_{4}(\mathrm{~K})$ & $2.427 \times 10^{-2}$ \\
\hline
\end{tabular}

The material density in these simulations is artificially increased by a factor of 10 to decrease the computational time. Compared to simulations performed with the actual density, a small amount of ringing in the normal stress components arises for the highest strain-rate case during the first $0.2 \mathrm{msec}$. The ringing also occurs when the strain rate is ramped down. Since the ringing is small, it does not significantly influence the plastic response and, thus, has negligible impact on this test problem. 


\section{FINITE ELEMENT (FE) RESULTS}

Figure 2 shows the equivalent plastic strain rate versus the equivalent plastic strain response for each of the four specimens contained in the test problem. Other than for some transient behavior, the strain rates are at their prescribed values and are constant with respect to the equivalent plastic strain and, hence, time. The responses confirm that the imposed boundary conditions are indeed generating the desired deformations in both space and time.

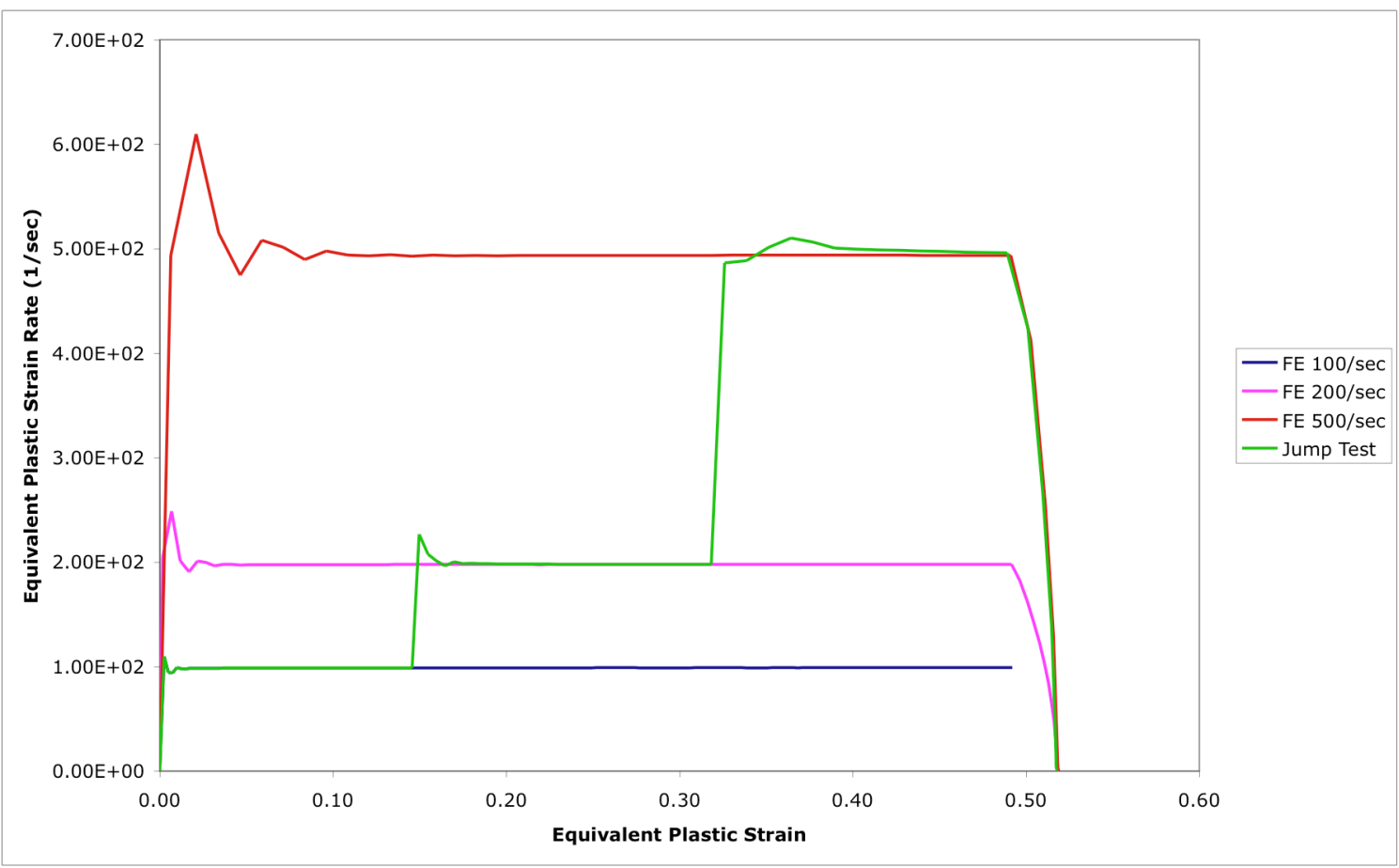

Figure 2. Equivalent plastic strain rate versus the equivalent plastic strain 
Figure 3 shows the effective stress versus the equivalent plastic strain from the FE simulations and from the mathematical relationship presented by Fehlmann (2005) and replicated by the above expressions. Clearly, there is excellent agreement between the theoretical and FE results even for the strain-rate jump case. The transient overshoot in plastic strain rate seen in Figure 2, due to its limited duration, only contributes to a minor overshoot in the effective stress and is really only visible for the 500/sec case in Figure 3 . The close agreement implies that the portion of the constitutive model associated with determining the current yield strength as a function of the strain rate, temperature, and the equivalent plastic strain is operating as intended. Furthermore, since there are specimens aligned with each of the three global coordinate axes, it appears that all normal stress and strain components in the constitutive relationship are functioning as desired.

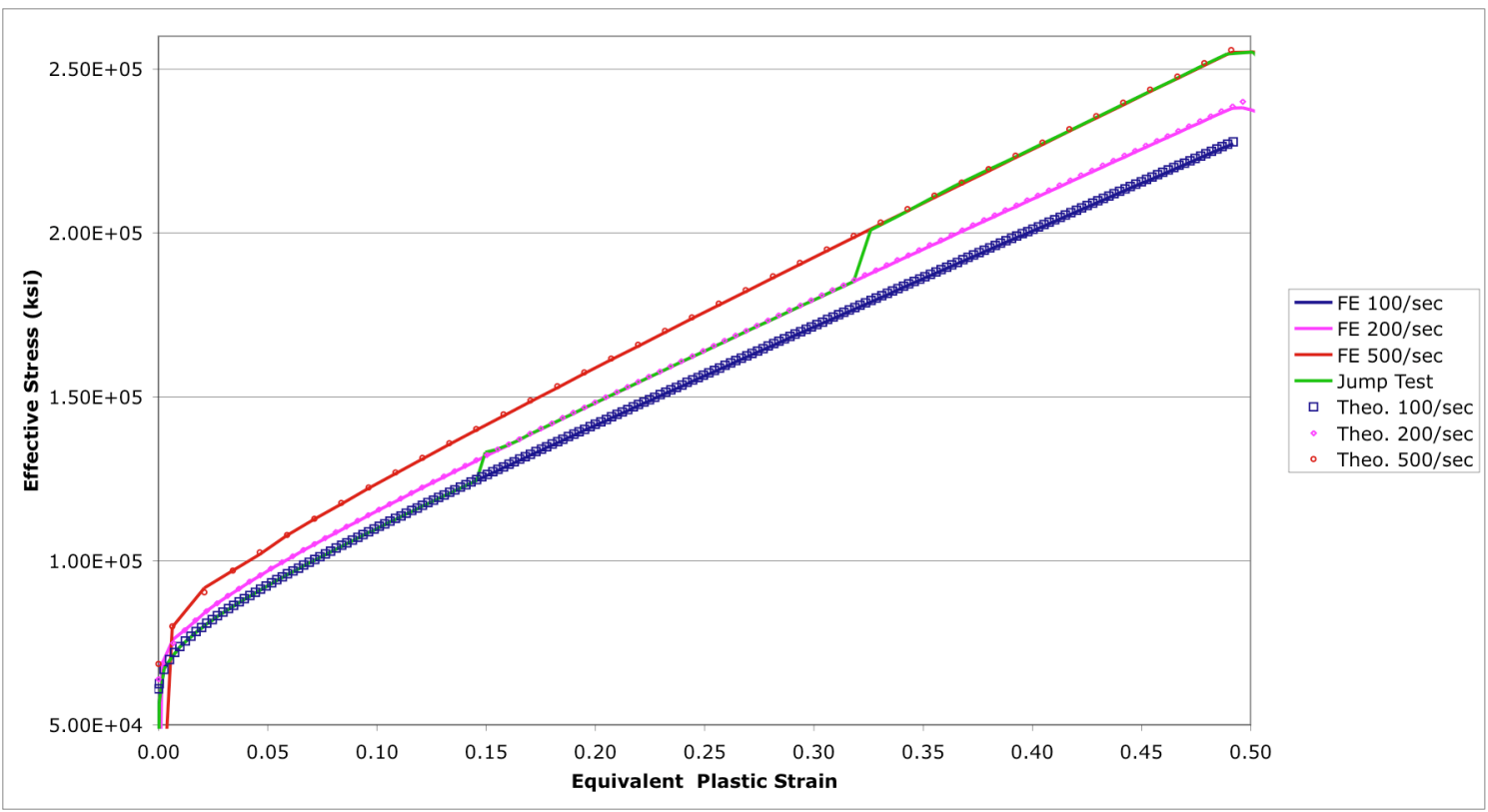

Figure 3. The effective stress versus equivalent plastic strain behavior for both FE simulations and theoretical responses. 
As can been seen in Figure 4, the axial stress and the effective stress are nearly identical during the entire simulation. Only during the first $0.2 \mathrm{msec}$ of the $500 / \mathrm{sec}$ case and after the strain-rate jumps does the axial stress seem to bounce a little about the effective stress response $(<5 \%)$. The effective stress versus plastic strain response is naturally smoother since there is an explicit relationship between these two quantities in the constitutive model. Nonetheless, the agreement demonstrated in Figure 4 further supports that the material model is operating correctly.

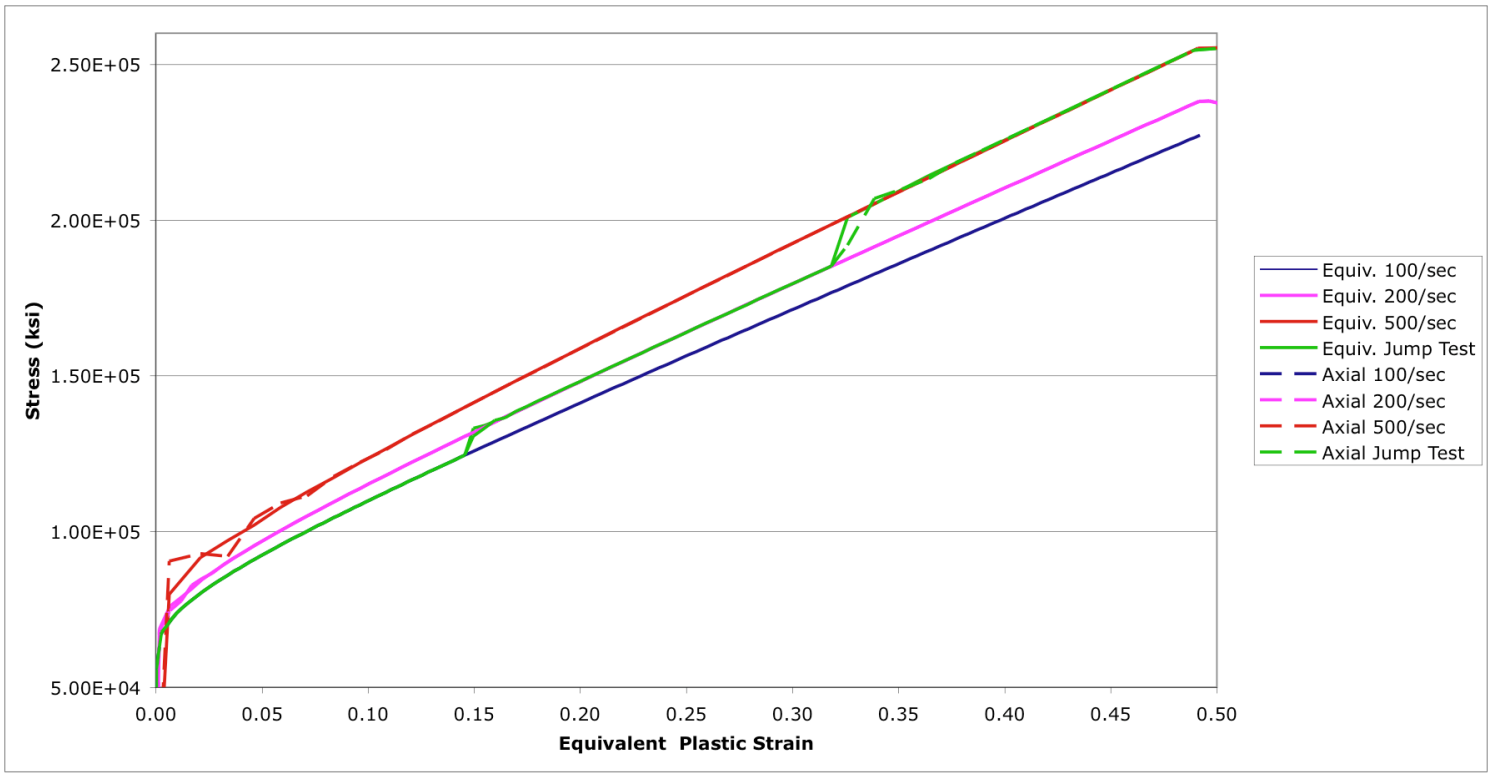

Figure 4. Effective and axial stresses versus the equivalent plastic strain

\section{REGRESSION TESTING}

The test problem described above is included in the DYNA3D test suite as problem $m k 71$ in the COUNT series. The effective stress at each of the four monitoring locations is written out, to sixteen significant digits, every $1 / 3^{\text {rd }}$ msec. These 16 sets of values are compared to stored values for regression testing purposes. 


\section{REFERENCES}

Whirley, R.G., and Engelmann, B.E., "DYNA3D: A Nonlinear, Explicit, ThreeDimensional Finite Element Code for Solid and Structural Mechanics, User Manual", University of California, Lawrence Livermore National Laboratory, UCRL-MA-107254 Rev. 1, 1993.

Fehlmann, K., "DYNA3D Material Model 24 Parameters for 21-6-9 Nitronic Steel at $60^{\circ} \mathrm{F}$ and $160^{\circ} \mathrm{F}$ " (U), University of California, Lawrence Livermore National Laboratory, Report CODTU-2005-1045, 2005.

Hodge, N. and Kay, G., "Verification of a Strain-Rate Dependent Material Model in DYNA3D and LS-DYNA" (U), University of California, UCRL-TR-202885, (Lawrence Livermore National Laboratory, Report CODTU-2003-1884), 2003.

Zywicz, E, "DYNA3D Material Model 24 - Solid Element Test Problem", University of California, Lawrence Livermore National Laboratory, Report UCRL-TR-224928, 2005. 